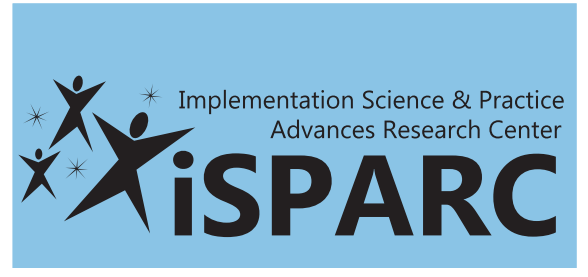

Tip Sheet

\title{
5 TIPS TO \\ TREATING WOMEN WITH PERINATAL DEPRESSION
}

A pproximately 1 in 7 women experience perinatal depression, a depressive episode that occurs during pregnancy or within the first year after delivery or adoption. Women with pre-pregnancy depression can experience a worsening of symptoms; while women who do not have a history of depression can experience it for the first time. The perinatal period is an ideal time to screen, diagnose, and treat depression as women have frequent and regular contact with their health care providers. Understanding the experiences of women who have experienced perinatal depression may help inform how health care professionals and organizations address this condition.

Research was done by iSPARC researchers, including national perinatal mental health expert Dr. Nancy Byatt.

Read more about iSPARC's research on parent and family mental health: https://www.umassmed.edu/sparc/ publications-and-products/issuebriefs-tip-sheets/parents-families/

To learn more about Dr. Byatt's work, you can visit the Lifeline4Moms Center website: umassmed.edu/lifeline4moms

For more resources and toolkits, please visit the MCPAP for Moms website: mcpapformoms.org

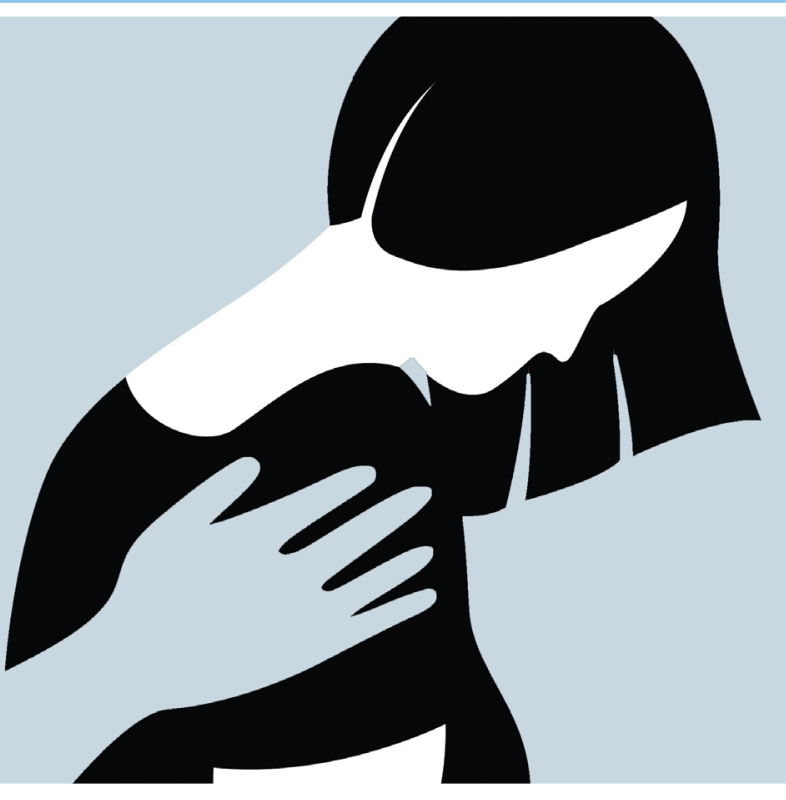

\section{THESE 5 TIPS FOR HEALTH CARE PROVIDERS ARE DIRECTLY FROM WOMEN WHO HAVE EXPERIENCED PERINATAL DEPRESSION:}

1. Let women know that perinatal depression is common and that the best thing they can do for themselves and their baby is to get the treatment they need and deserve.

2. Provide new moms with information about perinatal depression and discuss the symptoms.

3. Be knowledgeable about treatment options, including medication and non-medication treatments like therapy. Continue existing medication regimens as necessary.

4. Provide opportunities for mothers to process the birth experience; encourage them to discuss their experiences with you.

5. Ask mothers specific questions to learn about their mental health, such as:

- How are you sleeping?

- How are you eating?

- Are you crying during the day? If yes, how often?

- How are you coping with pregnancy and having a new baby? 